\title{
NEUTRON-INDUCED PROMPT GAMMA ACTIVATION ANALYSIS (PGAA) OF METALS AND NON-METALS IN OCEAN FLOOR \\ GEOTHERMAL VENT-GENERATED SAMPLES
}

D. L. Perry $^{1 *}$, R.B. Firestone ${ }^{1}$, G.L. Molnar ${ }^{2}, Z_{\text {Zs. Revay, }}^{2}$ Zs. Kasztovszky ${ }^{2}$, R. C. Gatti ${ }^{1}$, and P. Wilde $^{3}$, Lawrence Berkeley National Laboratory, ${ }^{1}$ Berkeley, CA, 94720 USA, Institute for Isotope and Surface Chemistry, ${ }^{2}$ H-1525 Budapest, POB 77, Hungary, and Pangloss Foundation, ${ }^{3}$ Berkeley, CA 94709.

\begin{abstract}
Neutron-induced prompt gamma activation analysis (PGAA) has been used to analyze ocean floor geothermal vent-generated samples that are composed of mixed metal sulfides, silicates, and aluminosilicates. The modern application of the PGAA technique is discussed, and elemental analytical results are given for 25 elements observed in the samples. The elemental analysis of the samples is consistent with the expected mineralogical compositions, and very consistent results are obtained for comparable samples. Special sensitivity to trace quantities of hydrogen, boron, cadmium, dysprosium, gadolinium, and samarium is discussed.
\end{abstract}

\section{INTRODUCTION}

Prompt Gamma-ray neutron Activation Analysis (PGAA) $)^{1-3}$ is a non-destructive, internallycalibrated, in situ, radio-analytical method capable of simultaneously identifying all elements from hydrogen to uranium, except helium, in solid, liquid, and gaseous samples. It exploits the prompt neutron capture gamma rays that are unique to each element unlike Neutron Activation Analysis (NAA), which is limited to decay gamma or beta rays from radioactive daughter nuclei from about 70 elements and is insensitive to the important elements $\mathrm{H}, \mathrm{B}, \mathrm{C}, \mathrm{N}, \mathrm{O}, \mathrm{P}, \mathrm{S}$, and $\mathrm{Pb}$. The PGAA method has been applied to materials science, chemistry, geology, mining, archaeology, environment, food analysis, medicine and other areas. Although not a new technique, its application 
was limited until recently when advancements in cold and thermal neutron beam technology, the development of a new capture gamma-ray database, and gamma ray detector advancements have increased PGAA sensitivity and made it possible to simultaneously and precisely analyze the relative elemental composition of materials in a low background environment. In most cases the relative concentrations of elements representing $>99 \%$ of the mass are determined allowing the absolute concentrations to be calculated.

This work has focused on the total elemental analysis of geothermal vent-generated metal sulfide, silicate, and aluminosilicate minerals using PGAA. We analyzed three samples retrieved from the Juan de Fuca Ridge and the East Pacific Rise ocean floor geothermal vents by the research

exploration vessel Alvin..$^{4-15}$ These samples are representative of the types of material retrieved in dives of the Alvin and thus give an excellent demonstration of complete, simultaneous, nondestructive, multi-element analysis with PGAA. The samples also provide an opportunity to look at a wide array of trace elements that may exhibit varying degrees of complexity in their chemistry. These samples were chosen to show the strength of the modern PGAA as a high sensitivity technique for performing elemental analyses of both the predominant elements and the extremely small chemical components in these highly heterogeneous materials.

\section{EXPERIMENTAL}

\section{PGAA Method}

PGAA is based on the nuclear phenomenon that cold or thermal neutrons captured on each element produce a spectrum of prompt gamma rays that is unique to the element. The elemental composition of a sample is determined by placing it in the neutron beam, measuring the gamma-ray spectrum with a Ge detector, and comparing the energies and intensities to the PGAA library of prompt gamma rays emitted by each element. Neutrons penetrate most materials uniformly, so PGAA provides the average elemental composition of the sample and is largely independent of the physical form of the sample being analyzed. Both the elemental and isotopic composition of solids, 
liquids, and gases can be obtained. Since the technique is non-destructive, no prior chemical or physical preparation is required, allowing for subsequent analyses with other methods.

\section{Experimental Apparatus}

The neutron-induced prompt gamma activation analyses (PGAA) were performed at the Institute for Isotope and Surface Chemistry, Budapest, Hungary, as described previously. ${ }^{16,17}$ The Budapest Reactor is a water-cooled, water-moderated research reactor with a thermal power of 10 MW. A curved neutron guide consisting of a glass coated nickel reflector transports the beam of low-energy neutrons to a low-background detector station approximately 35 meters from the reactor core where epithermal neutrons that would otherwise distort the spectrum are completely suppressed.

The prompt gamma-ray detector, located at the end of the guide, consists of high purity germanium (HPGe) detector which is surrounded by a bismuth germanate (BGO) scintillator annulus used to reject Compton-scattered photons. The thermal-equivalent effective flux is approximately $2.5 \times 10^{6} \mathrm{~cm}^{-2} \mathrm{~s}^{-1}$ at the target position. Samples were placed directly in the beam that was collimated to an area of $2 \times 2 \mathrm{~cm}$. The detector assembly can be moved to various positions, and the HPGe detector can be placed within $12 \mathrm{~cm}$ of the target. Complete details of the experimental arrangement and detector system are discussed elsewhere. ${ }^{17}$ The measured chemical composition of the sample is an average value for the entire irradiated volume of the sample which is uniformly irradiated by the neutrons.

Sample spectra are collected using a 16,000 channel multichannel analyzer from Canberra, Model No. S100 MCA. The gamma-ray energy and efficiency calibrations for the system are performed using standard lines from both radioactive sources and $(n, \gamma)$ reactions. The spectra from the ocean vent samples were analyzed with "Hypermet PC," a gamma-ray spectrum analysis program developed at the Institute for Isotope and Surface Chemistry in Budapest. ${ }^{18}$ 


\section{Element Identification}

The elemental identification is based on a comparison of the sample spectrum with the gamma ray database for all elements from hydrogen to uranium (except for helium) measured at the Institute for Isotope and Surface Chemistry, Budapest, Hungary ${ }^{19}$. This database is being combined with other data, as part of an International Atomic Energy Agency Cooperative Research Project, and will be released in 2003. The elements are qualitatively identified according to the energies of the most intense prompt-gamma peaks. As many as 25 gamma rays may be used to redundantly identify an element. The reliability of the element identification is controlled through an uncertainty weighted statistical comparison of the energies, comparison of the relative gamma-ray intensities with those in the database, and consideration of possible background contaminants originating from the $(\mathrm{n}, \gamma)$ reactions in the surrounding material. The most important background sources are from oxygen and nitrogen in the air, iron and aluminum in the counting station, and fluorine from the Teflon packaging material holding the samples. Natural background from the uranium and thorium

series and ${ }^{40} \mathrm{~K}$ also contribute to the spectra. Background spectra were recorded and are used to correct the analysis when necessary. At Lawrence Berkeley National Laboratory, a separate low background gamma-ray counting analysis of the geothermal vent samples found no detectable presence of either uranium or thorium.

\section{Determination of Chemical Composition}

The specific counting rate of a prompt gamma ray from neutron capture is given by

$$
A=\frac{N_{\gamma} / t_{m}}{m}
$$

and is usually expressed in units of counts $\mathrm{s}^{-1} \mathrm{~g}^{-1} \cdot N_{\gamma}$ is the integral number of counts during a time interval $t_{m}$ from a mass $m$ of an element. Following the convention used in neutron 
activation analysis, we define a $k_{0}$-factor relating the prompt gamma ray yields for each element $x$ to a comparator element $c$ by the equation

$$
k_{0, c}(x)=\frac{A_{x} / \varepsilon_{\gamma, x}}{A_{c} / \varepsilon_{\gamma, c}}=\frac{\theta_{x} \gamma_{x} \sigma_{0, x} / M_{x}}{\theta_{c} \gamma_{c} \sigma_{0, c} / M_{c}}
$$

where $\mathrm{M}$ is the atomic mass, $\theta$ is the isotopic abundance, $\sigma_{0}$ is the thermal neutron capture cross-section of the isotope, $\gamma$ is the number of gamma-rays emitted per neutron capture, and $\varepsilon_{\gamma}$ is the detector efficiency. Thermal cross sections are defined as $\sigma_{0}=\sigma \cdot v / v_{0}\left(v_{0}=2200 \mathrm{~m} \cdot \mathrm{s}^{-1}\right)$ for nearly all elements, so the velocity dependence cancels for cold and thermal beams irrespective of the neutron temperature.

The mass ratio for an element "x" can be determined by the following equation:

$$
\frac{m_{x}}{m_{R}}=\frac{A_{x}}{A_{R}} \frac{k_{0, c}(R)}{k_{0, c}(x)} \frac{\varepsilon_{R}}{\varepsilon_{x}}
$$

where $\mathrm{R}$ is an arbitrary reference element contained within the sample. This ratio is independent of the neutron flux and depends only on nuclear constants and the detector efficiency that are known with good accuracy. ${ }^{\mathbf{2 0}}$ The $k_{0}$-factors for all elements were determined by internal standardization measurements at the Budapest Reactor and are discussed elsewhere ${ }^{21}$.

The relative masses are calculated according to Equations (1)-(3). In neutron activation analysis, a standard comparator material must be measured with the sample to obtain an absolute calibration. This is not usually necessary for PGAA when all major elemental components are simultaneously determined and

$$
\sum_{x=H}^{U} m_{x}=m_{\text {sample }}
$$

where the arbitrary reference element cancels. 
The principal errors in determining the elemental concentrations include the statistical uncertainties of the peak areas, the $k_{0}$-factors, and the detector efficiencies. The latter two typically have standard deviations of a less than few percent, so the total uncertainty is mainly determined primarily by the counting statistics. The $k_{0}$ values in the database were measured with respect to the very well know hydrogen cross-section introducing a negligible systematic error of $0.2 \%$. Interferences from contaminant gamma rays are individually examined, and the affected peaks are either corrected for interference or neglected from the calculations. Corrections for gamma ray absorption in the sample may also be important, particularly for low energy gamma rays, and can be corrected using theoretical absorption data.

The concentration of each element is determined independently for each prompt gamma ray observed in the spectrum that has been assigned in the database to that element. In some cases more than 25 independent determinations can be performed for one element. Discrepant data that disagree because of contaminants or analytical difficulties are rejected, and the remaining measurements are averaged to give a final concentration. An example for a chlorine analysis of one of the geothermal vent samples is given in Table 1. We have previously performed comparisons of NIST certified and measured concentrations of SRM 1645 River Sediment $^{20}$ and obtained excellent agreement.

\section{Detection Limits}

PGAA elemental sensitivities depend on several factors including the thermal neutron cross section, counting statistics, background and interferences from other elemental constituents, the number of available prompt gamma ray calibration lines, and their energies and intensities. The peak analysis was performed using Hypermet PC that is typically used to find peaks that exceed

three times the standard deviation of the background. Yonezawa ${ }^{22}$ has proposed estimated 
detection limits for each element, based on the cross section yields of the most intense gamma rays, which is shown in Table 2.

\section{Measurements of the Geothermal Vent Samples}

Three geothermal vent samples were obtained from the East Pacific Rise and Juan de Fuca Ridge geothermal fields by the U.S. Geological Survey, Menlo Park, CA, as previously reported. ${ }^{5-15}$ The samples that were analyzed in this study were as follows. Sample 917-R4: Taken from East Pacific Rise Operations Area on Alvin Dive Number 917 on April 24, 1979; Latitude: 2049.9’N; Longitude: 109².8W'; Sample 1457-1R-C: Taken from Juan de Fuca Operations Area on Alvin

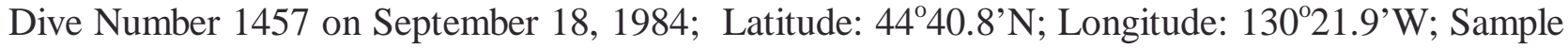
1461-2R: Taken from Juan de Fuca Operations Area on Alvin Dive Number 1461 on September 28, 1984; Latitude: $44^{\circ} 40^{\prime} \mathrm{N}$; Longitude: $130^{\circ} 22^{\prime} \mathrm{W}$. Elemental compositions of the ocean geothermal vent samples were analyzed by means of PGAA as described above. The irregularly

shaped individual samples, weighing between 12 and $15 \mathrm{~g}$, were placed in the neutron beam, and Compton suppressed prompt gamma-ray spectra were measured. The samples were sealed in thin Teflon bags selected to minimize contamination from the container. Sample 1457-1R-C was irradiated for 54,400 seconds, sample 1461-2R for 7100 seconds, and sample 917-R4 for 7300 seconds.

\section{RESULTS AND DISCUSSION}

The neutron-induced PGAA technique employed here is able to analyze for all major constituents with concentration $>100 \mathrm{mg} / \mathrm{g}$ and many trace elements in the samples. The spectra obtained are shown in Figure 1a-1c where some of the prominent gamma rays have been labeled by their element identification. The elemental concentrations obtained from an analysis of these spectra are given in Table 3 .

Samples 1457-1R-C and 1461-2R were remarkably similar, being composed mainly of silicate and aluminosilicate materials. These samples were found in close proximity in the 
geothermal field, thus explaining their similarity. Sample 917-R4 contained little silicon, no measurable aluminum, and was mainly composed of copper, nickel and zinc sulfides not found in the other samples. These analyses are consistent with the overall mineralogical analyses of other vent samples that were collected from the two geothermal fields that were previously reported ${ }^{5-15}$. In addition to the major elements in these samples, trace amounts of many other elements were also detected. Notably, the rare earth elements samarium, and gadolinium had similar concentrations in all three samples, while dysprosium was only seen in samples ALVIN 1457-1R-C and ALVIN 1461-2R. These results show the variability of rare earth concentrations from roughly the same ocean bed geothermal field and demonstrate the particular sensitivity of PGAA to these elements. Hydrogen, boron, and cadmium were also found at the trace level in all three samples, showing the great sensitivity of PGAA to these elements.

The analytical results obtained here by PGAA compare favorably with the capabilities of other more widely accessible standard laboratory-based analytical techniques such as x-ray, Auger, or other types of microprobe methods that are often used to analyze samples of this type. Those approaches are normally position-sensitive, yielding data for only a small region of the specimen being analyzed. Other spectroscopic analytical techniques such as X-ray photoelectron spectroscopy (XPS, also sometimes called electron spectroscopy for chemical analysis, or ESCA), and x-ray fluorescence are surface-sensitive techniques, and vibrationally based spectroscopies such as infrared and Raman give spectra that do not generally mirror the entire body of the sample. Neutron activation analysis is similar to PGAA and sensitive to very low concentrations, but it is limited to only a few elements and tends to create very radioactive products. ICP-MS is a competitive method to PGAA; however, it is a destructive method for multielement analysis, too. Conversely, PGAA analyzes the elemental composition of the entire sample nondestructively allowing the use of alternative techniques for complimentary the analysis.

\section{CONCLUSION}


Prompt-gamma activation analysis has been shown to be an effective method to simultaneously determine both macro- and micro quantities of many elements that are contained in geothermal ocean vent samples found on the ocean's floor. The elemental analyses are consistent with previously reported mineralogical and chemical phases involving sulfides, silicates, aluminosilicates, and analysis of similar samples is shown to give consistent results. The promptgamma ray activation analysis approach has major advantages over other analytical approaches, because PGAA is nondestructive and provides results that are representative for the entire sample volume. 


\section{ACKNOWLEDGMENTS}

This work was supported by the U. S. Department of Energy under Contract Number DEAC03-76SF00098 and the U. S. Hungarian Joint Fund under Program No. 429. The authors wish to acknowledge William R. Normark for helpful discussions.

\section{REFERENCES}

1. R. M. Lindstrom and C. Yonezawa, in Prompt Gamma Neutron Activation Analysis, Z.B. Alfassi and C. Chung, Eds., CRC Press, Boca Raton, FL, 1995, p. 93.

2 G. L. Molnar and R. M. Lindstrom, in Nuclear Methods in Mineralogy and Geology, A. Vertes, S. Nagy, and K. Suvegh, Eds., Plenum Press, New York, 1998, p. 145.

3. Prompt Gamma Neutron Activation Analysis, Z.B. Alfassi and C. Chung, Eds., CRC Press, Boca Raton, FL, 1995,

4. F. N. Spiess, K. C. Macdonald, T. Atwater, R. Ballard, A. Carranza, D. Cordoba, C. Cox, V. M. Diaz-Garcia, J. Francheteau, J. Guerrero, J. Hawkins, R. Haymon, R. Hessler, T. Juteau, M. Kastner, R. Larson, B. Luyendyk, J. D. Macdougall, S. Miller, W. Normark, J. Orcutt, and C. Rangin, Science, 1980, 207, 1421.

5. R. Hekenian, M. Fevrier, J. L. Bischoff, P. Picot, and W. C. Shanks, Science, 1980, 207, 1433.

6. V. Tunnicliffe and A. R. Fontaine, J. Geophys. Res. 92, B11, 1987, 11,303.

7. J. A. Philpotts, P. J. Aruscavage, and K. L. Von Damm, J. Geophys. Res. 92, B11, 1987, 11,327 .

8. K. L. von Damm and J. L. Bischoff, J. Geophys. Res. 92, B11, 1987, 11,334. 
9. R. A. Feely, M. Lewison, G. J. Massoth, G.Robert-Baldo, J. W. Lavelle, R. H. Byrne, K. L. von Damm, and H. C. Curl, Jr., J. Geophys. Res. 92, B11, 1987, 11,347.

10. J. N. V-Silver, F. Terra, J. Klein, and R. Middleton, J. Geophys. Res. 92, B11, 1987, 11,364 .

11. R. Brett, H. T. Evans, Jr., E. K. Gibson, Jr., J. W. Hedenquist, M. V. Wandless, and M. A. Sommer, J. Geophys. Res. 92, B11, 1987, 11,373.

12. E. Hegner and M. Tatsumoto, J. Geophys. Res. 92, B11, 1987, 11,380.

13. W. C. Shanks III and W. E. Seyfried, Jr., J. Geophys. Res. 92, B11, 1987, 11,387.

14. T. K. Hinkley and M. Tatsumoto, J. Geophys. Res. 92, B11, 1987, 11,400.

15. J. H. Chen, J. Geophys. Res. 92, B11, 1987, 11,411.

16. G. L. Molnar, T. Belgya, L. Dabolczi, B. Fazekas, A. Veres, I. Bikit, Z. Kiss, and J. Ostor, J. Radioanal. Nucl. Chem., 1997, 215, 111.

17. T. Belgya, Zs. Revay, B. Fazekas, I. Hejja, L. Dabolczi, G. L. Molnar, Z. Kiss, J. Ostor, and Gy. Kaszas, in Proceedings of the 9th International Symposium on Capture Gamma-Ray Spectroscopy and Related Topics, G. L. Molnar, T. Belgya, and Zs. Revay, Eds., Springer Hungarica, Budapest, 1997, p. 826; also, see the Website at http://www.iki.kfki.hu/nuclear/ for photographic details.

18. B. Fazekas, G. L. Molnar, T. Belgya, L. Dabolczi, and A. Simonits, J. Radioanal. Nucl. Chem., 1997, 215, 271.

19. G. L. Molnar, Zs. Revay, T. Belgya, Zs. Kasztovszky, and R. B. Firestone, App. Radiation Isotopes., 2000, 53, 527.

20. G. L. Molnar, Zs. Revay, R. L. Paul, and R. M. Lindstrom, J. Radioanal. Nucl. Chem., 1998, 234, 21.

21. Zs. Revay, G. L. Molnar, T. Belgya, Zs. Kasztovszky, and R. B. Firestone, J. Radioanal. Nucl. Chem., 2000, 244, 383. 
22. C. Yonezawa, Anal. Sci., 1993, 9, 185. 
Figure 1. Prompt Gamma-ray Activation Analysis (PGAA) spectra for the three ocean vent samples a) ALVIN 917-R4, b) ALVIN 1457-1R-C, and c) ALVIN 1461-2R. Prominent gamma lines representative of some of the observed elements are labeled accordingly. Escape peaks from annihilation radiation $(511 \mathrm{KeV})$ escaping the detector following pair production are indicated by Esc. The aluminum peak at $1779 \mathrm{keV}$ is from the short-lived $\mathrm{t}_{1 / 2}=2.2 \mathrm{~min}$, decay produced by Neutron Activation Analysis (NAA) during the PGAA experiments. 


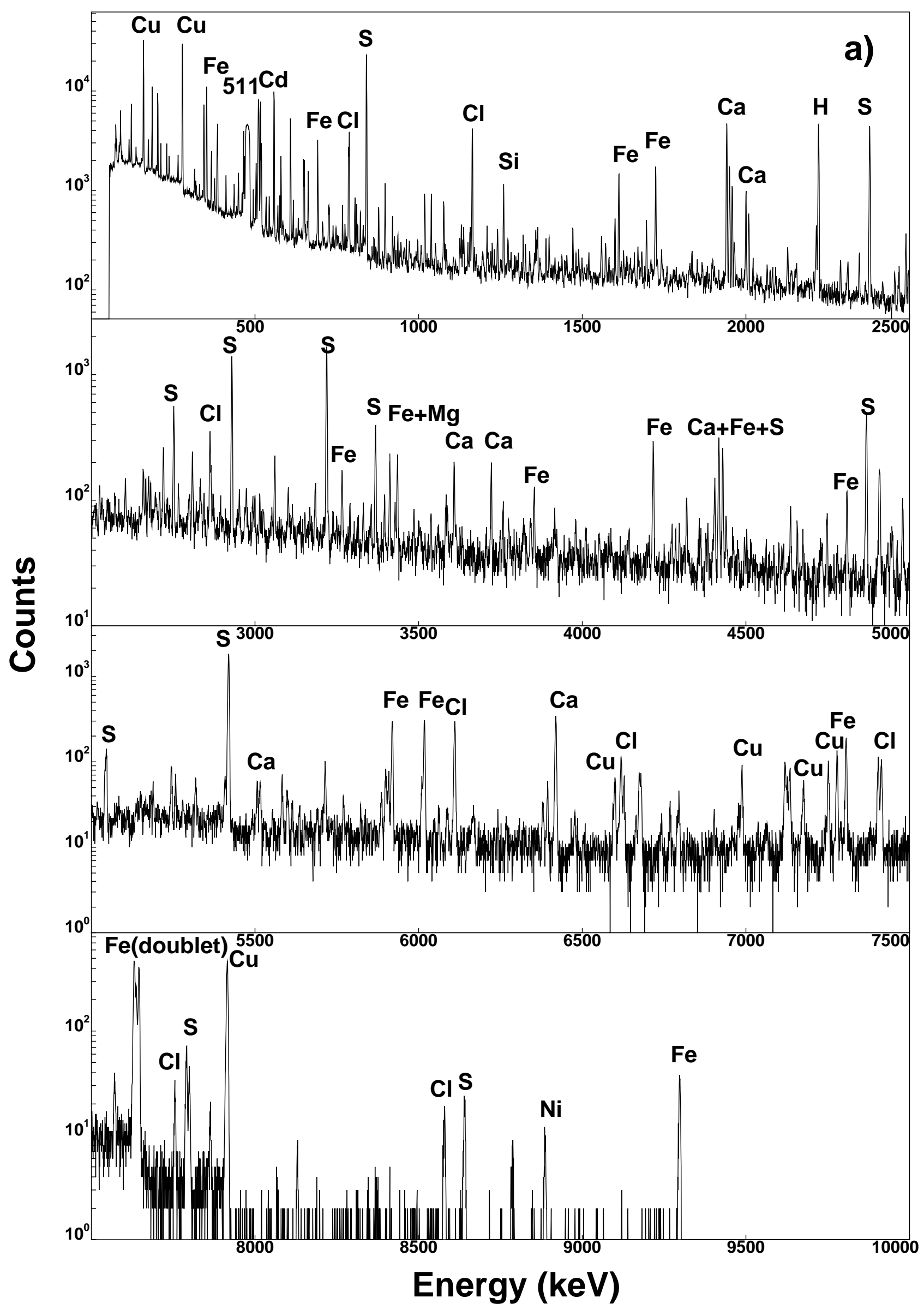




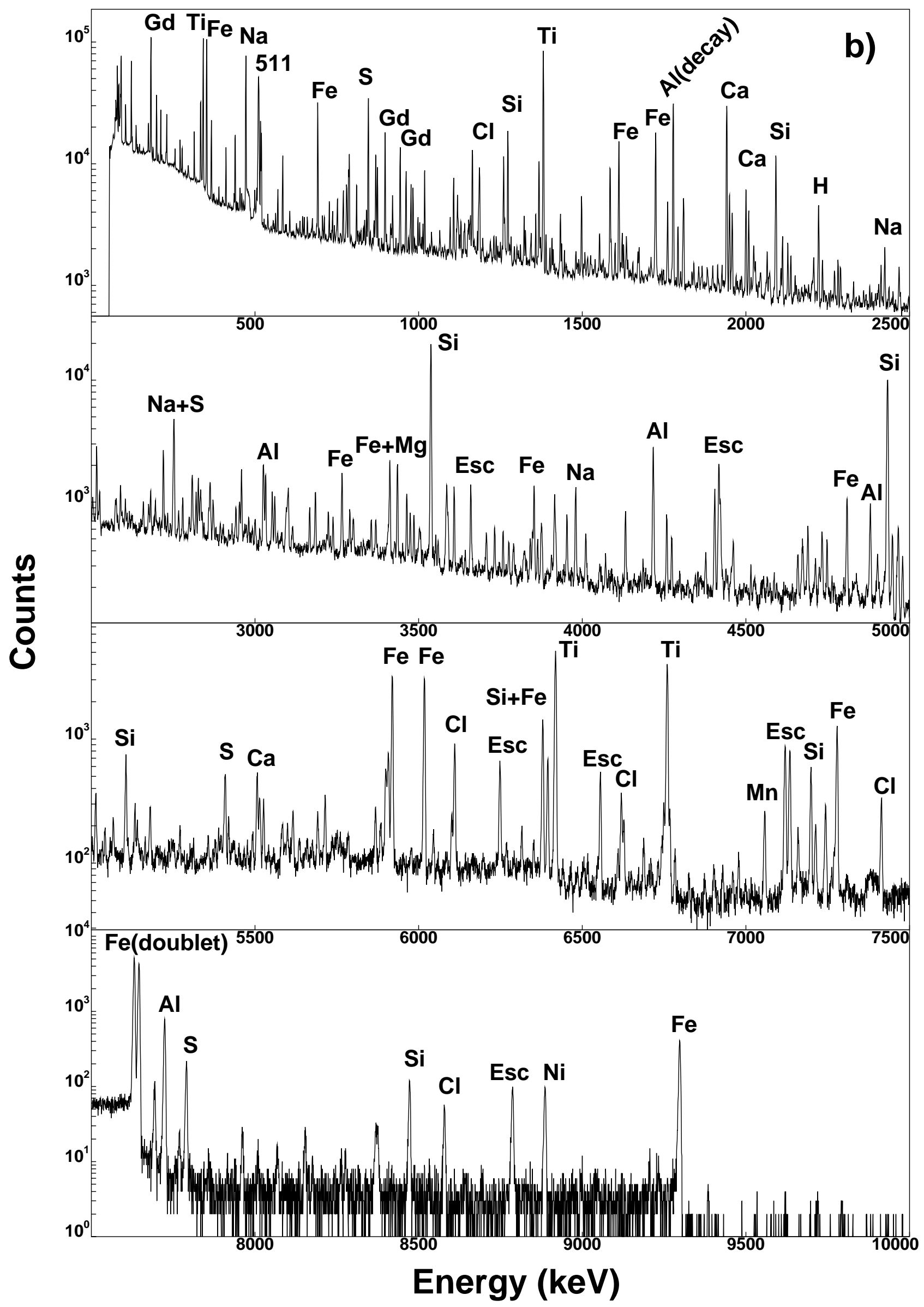




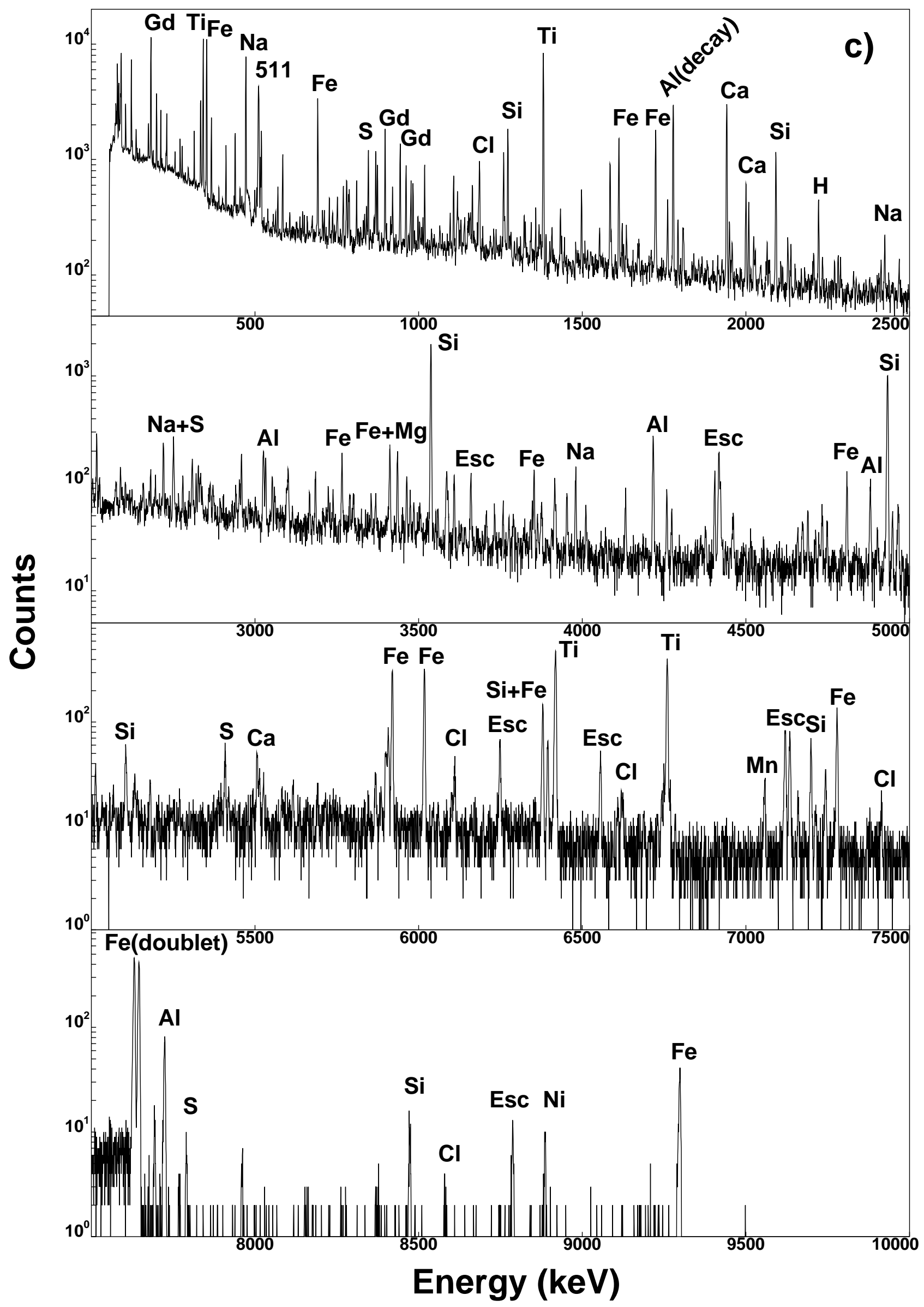


Table 1. The analysis of chlorine in geothermal vent sample ALVIN 917-R4. The twenty-five most intense prompt gamma-ray transitions for chlorine were matched from the measurement (Column 2) to the database (Column 3) by energy (keV). The relative transition intensities and percent uncertainties from the database and experiment are shown in Column 4 and 5. The net sample chlorine mass, calculated for each gamma ray, is shown in Column 6. The gamma rays that were free of interferences and selected for this analysis are indicated in Column 7. The weighted average result from 22 gamma rays is shown at the bottom of this table. The correction for background chlorine $(0.1 \%)$ is negligible.

\begin{tabular}{|c|c|c|c|c|c|c|}
\hline No. & $E_{\text {expt }} d E$ & $E_{\text {data }} d E$ & $I_{\text {data }} d I(\%)$ & $\mathrm{I}_{\text {expt }} d \mathrm{I}(\%)$ & Mass(mg) & Selected \\
\hline 1 & 1164.820 .04 & 1164.830 .01 & 100.00 .7 & 100.01 .4 & 0.0182 & * \\
\hline 2 & 517.120 .03 & 517.080 .01 & 83.20 .9 & 81.61 .9 & 0.0178 & * \\
\hline 3 & 6110.830 .16 & 6110.710 .07 & 82.61 .4 & 82.02 .4 & 0.0180 & * \\
\hline 4 & 1951.090 .05 & 1951.150 .02 & 72.70 .8 & 71.31 .9 & 0.0178 & * \\
\hline 5 & 788.410 .03 & 788.370 .21 & 55.047 .2 & 59.81 .4 & 0.0198 & * \\
\hline 6 & 1959.300 .06 & 1959.360 .02 & 46.90 .9 & 45.62 .3 & 0.0176 & * \\
\hline 7 & 786.260 .04 & 786.180 .15 & 40.547 .9 & 39.31 .7 & 0.0176 & * \\
\hline 8 & 7414.020 .21 & 7413.920 .10 & 40.01 .8 & 41.04 .0 & 0.0187 & * \\
\hline 9 & 7790.350 .22 & 7790.280 .11 & 32.42 .1 & 29.14.4 & 0.0163 & * \\
\hline 10 & 6618.930 .20 & 6619.580 .08 & 30.81 .6 & 41.25 .0 & 0.0243 & \\
\hline 11 & 5715.010 .18 & 5715.160 .07 & 20.91 .9 & 19.06 .1 & 0.0165 & * \\
\hline 12 & 2863.870 .10 & 2863.760 .03 & 20.51 .4 & 23.15.9 & 0.0204 & * \\
\hline 13 & 6627.740 .24 & 6627.870 .08 & 17.51 .9 & 19.08 .1 & 0.0197 & * \\
\hline 14 & 4979.720 .21 & 4979.750 .05 & 14.11 .9 & 15.47 .4 & 0.0198 & * \\
\hline 15 & 1601.010 .06 & 1601.060 .01 & 13.81 .2 & 13.84 .2 & 0.0182 & * \\
\hline 16 & 3061.740 .13 & 3061.760 .03 & 12.41 .7 & 13.65 .8 & 0.0200 & * \\
\hline 17 & 8578.260 .30 & 8578.580 .15 & 10.42 .8 & 9.98 .0 & 0.0173 & * \\
\hline 18 & 6978.180 .50 & 6977.750 .10 & 8.92 .6 & 5.620 .6 & 0.0114 & \\
\hline 19 & 1162.650 .10 & 1162.560 .05 & 7.93.7 & 7.79.2 & 0.0177 & * \\
\hline 20 & 1131.140 .08 & 1131.180 .02 & 7.11 .5 & 7.66 .0 & 0.0194 & * \\
\hline 21 & 5516.350 .25 & 5517.130 .08 & 6.52 .9 & 12.47 .7 & 0.0350 & \\
\hline 22 & 2676.060 .14 & 2676.110 .03 & 5.92 .0 & 6.010 .6 & 0.0187 & * \\
\hline 23 & 5904.370 .69 & 5902.750 .11 & 4.73 .8 & 3.628 .2 & 0.0140 & * \\
\hline 24 & 1327.380 .13 & 1327.360 .02 & 4.51 .7 & 4.58 .9 & 0.0179 & * \\
\hline 25 & 4943.190 .29 & 4944.350.06 & 4.32.4 & 4.815.3 & 0.0204 & * \\
\hline
\end{tabular}

Average 
Table 2. Sensitivity (S) and detection limits (DL) for selected gamma rays calculated by Yonezawa $^{22}$, for most elements, with the JAERI cold neutron beam. Gamma rays designated by D are from short-lived radioisotopes produced during the PGAA measurement. Sensitivity and detection limit may vary depending on the neutron flux, counting statistics, gamma-ray selection, and interferences in the spectrum.

\begin{tabular}{cccc|cccc}
\hline Element & $\mathbf{E} \boldsymbol{\gamma}$ & $\mathbf{S}(\mathbf{c p s} / \mathbf{m g})$ & $\mathbf{D L}(\boldsymbol{\mu g} \mathbf{g} \mathbf{g})$ & $\mathbf{E l e m e n t}$ & $\mathbf{E} \boldsymbol{\gamma}$ & $\mathbf{S}(\mathbf{c p s} / \mathbf{m g})$ & $\mathbf{D L}(\boldsymbol{\mu g} \mathbf{g} \mathbf{g})$ \\
\hline $\mathrm{H}$ & 2223 & 3.14 & 1.3 & $\mathrm{Ru}$ & 540 & 0.278 & 11 \\
$\mathrm{Li}$ & 2032 & 0.0467 & 24 & $\mathrm{Pd}$ & 717 & 0.169 & 19 \\
$\mathrm{Be}$ & 6809 & 0.00566 & 49 & $\mathrm{Ag}$ & 198 & 5.21 & 1.7 \\
$\mathrm{~B}$ & 478 & 2300 & 0.0025 & $\mathrm{Cd}$ & 558 & 403 & 0.0108 \\
$\mathrm{C}$ & 1262 & 0.0029 & 807 & $\mathrm{In}$ & 273 & 13.5 & 0.39 \\
$\mathrm{~N}$ & 5269 & 0.007 & 115 & $\mathrm{Sn}$ & 1293 & 0.0178 & 110 \\
$\mathrm{~F}$ & $1634 \mathrm{D}$ & 0.0272 & 267 & $\mathrm{Sb}$ & 283 & 0.108 & 40 \\
$\mathrm{Na}$ & 473 & 0.867 & 4.7 & $\mathrm{Te}$ & 603 & 0.609 & 11 \\
$\mathrm{Mg}$ & 3918 & 0.00752 & 73 & $\mathrm{I}$ & 134 & 1.04 & 10 \\
$\mathrm{Al}$ & $1779 \mathrm{D}$ & 0.11 & 15 & $\mathrm{Ba}$ & 1436 & 0.0311 & 41 \\
$\mathrm{Si}$ & 3540 & 0.0298 & 23 & $\mathrm{La}$ & 218 & 0.338 & 22 \\
$\mathrm{P}$ & 513 & 0.0909 & 54 & $\mathrm{Ce}$ & 662 & 0.0956 & 29 \\
$\mathrm{~S}$ & 841 & 0.253 & 15 & $\mathrm{Pr}$ & 177 & 0.548 & 14 \\
$\mathrm{Cl}$ & 1165 & 3.6 & 0.79 & $\mathrm{Nd}$ & 697 & 7.99 & 0.68 \\
$\mathrm{~K}$ & 770 & 0.574 & 3.1 & $\mathrm{Sm}$ & 334 & 749 & 0.0071 \\
$\mathrm{Ca}$ & 1942 & 0.0546 & 18 & $\mathrm{Eu}$ & $90 \mathrm{D}$ & 740 & 0.047 \\
$\mathrm{Sc}$ & 228 & 14.9 & 0.65 & & 221 & 25.7 & 0.34 \\
$\mathrm{Ti}$ & 1381 & 1.9 & 0.79 & $\mathrm{Gd}$ & 182 & 1564 & 0.0064 \\
$\mathrm{~V}$ & 125 & 2.85 & 3.9 & $\mathrm{~Tb}$ & 352 & 0.11 & 24 \\
& $1434 \mathrm{D}$ & 1.69 & 0.7 & $\mathrm{Dy}$ & 186 & 67.4 & 0.11 \\
$\mathrm{Cr}$ & 835 & 0.688 & 3.9 & $\mathrm{Ho}$ & 137 & 7.2 & 1.8 \\
$\mathrm{Mn}$ & 212 & 2.67 & 2.7 & $\mathrm{Er}$ & 816 & 4.55 & 0.35 \\
$\mathrm{Fe}$ & 352 & 0.229 & 28 & $\mathrm{Tm}$ & 205 & 3.17 & 1.9 \\
$\mathrm{Co}$ & 556 & 2.92 & 0.94 & $\mathrm{Yb}$ & 515 & 2.53 & 1.8 \\
$\mathrm{Ni}$ & 465 & 0.558 & 5.1 & & 636 & 0.277 & 5.9 \\
$\mathrm{Cu}$ & 278 & 0.789 & 6.4 & $\mathrm{Lu}$ & 458 & 1.1 & 2.7 \\
$\mathrm{Zn}$ & 1078 & 0.107 & 15 & $\mathrm{Hf}$ & $214 \mathrm{D}$ & 14 & 0.57 \\
$\mathrm{Ga}$ & 508 & 0.174 & 28 & $\mathrm{Ta}$ & 270 & 1.29 & 4.3 \\
$\mathrm{Ge}$ & 596 & 0.393 & 13 & $\mathrm{~W}$ & 146 & 0.583 & 18 \\
$\mathrm{As}$ & 165 & 1.13 & 8.7 & $\mathrm{Re}$ & 208 & 1.2 & 5.7 \\
$\mathrm{Se}$ & 614 & 0.796 & 4.4 & $\mathrm{Ir}$ & 352 & 0.144 & 19 \\
$\mathrm{Br}$ & 245 & 0.919 & 6.5 & $\mathrm{Pt}$ & 356 & 1.22 & 3 \\
$\mathrm{Sr}$ & 1837 & 0.134 & 7 & $\mathrm{Au}$ & 215 & 1.36 & 4.5 \\
$\mathrm{Y}$ & 777 & 0.167 & 11 & $\mathrm{Hg}$ & 368 & 53.7 & 0.055 \\
$\mathrm{Zr}$ & 934 & 0.0261 & 71 & $\mathrm{Tl}$ & 348 & 0.0691 & 46 \\
$\mathrm{Nb}$ & 256 & 0.0795 & 53 & $\mathrm{~Pb}$ & 7368 & 0.00147 & 240 \\
$\mathrm{Mo}$ & 778 & 0.465 & 3.8 & $\mathrm{Bi}$ & 320 & 0.00172 & 2200 \\
\hline & & & & & & &
\end{tabular}


Table 3. Percent elemental concentrations ( $\mathrm{g} / 100 \mathrm{~g}$ sample) for the three ocean vent samples. Oxygen values marked with an asterisk were calculated from the expected oxidation states for the observed elements. The $\mathrm{k}_{0}$ factors for oxygen are too small for an accurate direct determination, so a systematic error of $\sim 2 \%$ should be added to the statistical errors which are given in parentheses.

\begin{tabular}{llll} 
& ALVIN 917-R4 & ALVIN 1457-1R-C & ALVIN 1461-2R \\
\hline $\mathbf{O}$ & $45.9^{*}$ & $41(6), 44.9^{*}$ & $57(15), 45.1^{*}$ \\
$\mathbf{S}$ & $20.0(0.2)$ & $0.151(0.005)$ & $0.16(0.01)$ \\
$\mathbf{C a}$ & $11.3(0.2)$ & $7.22(0.11)$ & $7.25(0.13)$ \\
$\mathbf{F e}$ & $9.28(0.11)$ & $9.65(0.08)$ & $9.37(0.09)$ \\
$\mathbf{C u}$ & $7.67(0.07)$ & --- & --- \\
$\mathbf{A l}$ & --- & $7.10(0.07)$ & $7.06(0.12)$ \\
$\mathbf{M g}$ & $1.8(0.2)$ & $3.98(0.11)$ & $3.6(0.2)$ \\
$\mathbf{Z n}$ & $1.36(0.05)$ & --- & --- \\
$\mathbf{P}$ & --- & $0.85(0.18)$ & $1.6(0.2)$ \\
$\mathbf{N i}$ & $1.17(0.003)$ & $0.022(0.002)$ & --- \\
Ti & --- & $1.097(0.008)$ & $1.060(0.010)$ \\
$\mathbf{S i}$ & $0.55(0.05)$ & $22.6(0.3)$ & $22.3(0.3)$ \\
$\mathbf{H}$ & $0.368(0.004)$ & $0.0290(0.0005)$ & $0.027(0.001)$ \\
$\mathbf{K}$ & $0.27(0.06)$ & $0.138(0.004)$ & $0.16(0.01)$ \\
$\mathbf{C l}$ & $0.194(0.002)$ & $0.0566(0.0005)$ & $0.0188(0.0005)$ \\
$\mathbf{M n}$ & --- & $0.154(0.002)$ & $0.161(0.004)$ \\
$\mathbf{N a}$ & $0.140(0.014)$ & $1.97(0.04)$ & $1.96(0.05)$ \\
$\mathbf{V}$ & --- & $0.042(0.002)$ & $0.046(0.003)$ \\
$\mathbf{C o}$ & $0.0066(0.0011)$ & $0.0045(0.0003)$ & $0.0058(0.0009)$ \\
Sc & --- & $0.0039(0.0002)$ & $0.0058(0.0005)$ \\
$\mathbf{C d}$ & $0.00352(0.00005)$ & --- & $0.00024(0.00003)$ \\
$\mathbf{B}$ & $0.00220(0.00002)$ & $0.000659(0.000007)$ & $0.000658(0.000008)$ \\
$\mathbf{D y}$ & --- & $0.00099(0.00008)$ & $0.00111(0.00014)$ \\
$\mathbf{G d}$ & $0.000050(0.000006)$ & $0.000524(0.000007)$ & $0.000556(0.000010)$ \\
$\mathbf{S m}$ & $0.00033(0.00003)$ & $0.000330(0.000005)$ & $0.000340(0.000007)$ \\
\hline & & &
\end{tabular}

